\title{
Dual pathways for induction of wingless expression by protein kinase $A$ and Hedgehog in D rosophila embryos
}

\author{
Johanna Talavera Ohlmeyer and Daniel Kalderon ${ }^{1}$ \\ Department of Biological Sciences, Columbia University, N ew York, N ew York 10027 USA
}

The secreted D rosophila Hedgehog $(\mathrm{Hh})$ protein induces transcription of specific genes by an unknown mechanism that requires the serpentine transmembrane protein Smoothened (Smo) and the transcription factor Cubitus interruptus (Ci). Protein kinase A (PKA) has been implicated in the mechanism of Hh signal transduction because it acts to repress $\mathrm{Hh}$ target genes in imaginal disc cells that express $\mathrm{Ci}$. Changes in $\mathrm{Ci}$ protein levels, detected by an antibody that recognizes an epitope in the carboxy-terminal half of $\mathrm{Ci}$, have been suggested to mediate the positive effects of $\mathrm{Hh}$ and the negative effects of PKA on Hh target gene expression in imaginal discs. Here we show that PKA inhibition, like Hh, leads to increased "carboxy-teminal" Ci staining and Hh target gene expression in embryos. In addition, we find that Hh and Smo can stimulate target gene expression at constant $\mathrm{Ci}$ levels and that increased PKA activity can induce ectopic Hh target gene expression in a manner that requires Smo and $\mathrm{Ci}$ activities but does not involve changes in $\mathrm{Ci}$ protein concentration. This suggests a branching pathway of Hh signal transduction downstream of Smo and that PKA exerts opposite effects on the two branches. Finally we show that Hh signaling in embryos does not depend on CAMP-dependent regulation of PKA activity.

[Key Words: Protein kinase A; Hedgehog; Cubitus interruptus; Drosophila; signal transduction; development]

Received June 16, 1997; revised version accepted July 14, 1997.

Secreted proteins of the Hedgehog family act as key inducing agents in both vertebrates and invertebrates, often influencing position-dependent cell fate over a large fiel d of cells (Ingham 1995). In some cases, including the Drosophila ventral embryonic ectoderm and larval imagi nal discs, Hedgehog $(\mathrm{Hh})$ acts locally to induce the synthesis of other secreted molecules, of the Wnt or transforming growth factor- $\beta$ (TGF- $\beta$ ) families, that relay the influence of $\mathrm{Hh}$ to more distant cells (Lawrence and Struhl 1996). In other cases, Hh may act directly over several cell diameters, inducing concentration-dependent responses (Heemskerk and DiNardo 1994; Roelink et al. 1995; Ericson et al. 1996; Struhl et al. 1997). The direct range of action of $\mathrm{Hh}$ is limited by post-translational modifications to $\mathrm{Hh}$ itself and by binding to the $\mathrm{Hh}$-receptor, Patched (Ptc), the product of a $\mathrm{Hh}$-inducible gene (Chen and Struhl 1996; Porter et al. 1996). Genetic and biochemical interactions among $\mathrm{Hh}, \mathrm{Ptc}$, and Smoothened (Smo) suggest that binding of $\mathrm{Hh}$ to Ptc leads to activation of Smo, a predicted seven-transmembrane domain protein presumed to interact with a $\mathrm{G}$ protein (Alcedo et al. 1996; Chen and Struhl 1996; M arigo et al. 1996; Stone et al. 1996; van den Heuvel and Ingham 1996). Although protein kinases such as Fused (Fu) and

${ }^{1}$ Corresponding author.

E-MAIL ddk1@columbia.edu; FAX (212) 865-8246. protein kinase $\mathrm{A}$ (PKA) are genetically implicated in $\mathrm{Hh}$ signaling, there is no evidence at present that their activities are altered by Hh signaling (Préat et al. 1990; Forbes et al . 1993; Jiang and Struhl 1995; Kal deron 1995; Lepage et al. 1995; Li et al. 1995; Pan and Rubin 1995; Strutt et al. 1995). Hh can signal normally in imaginal disc cells if PKA is manipulated to be unresponsive to CAM P (Jiang and Struhl 1995; Li et al. 1995) or if animals lack activity of both Fu and another gene product, Suppressor of Fused (Préat 1992; Thérond et al. 1996a).

The zinc finger protein, Cubitus interruptus $(\mathrm{Ci})$ has DNA-binding activity that is essential to transduction of a Hh signal, suggesting that it acts as a key transcriptional activator (Forbes et al. 1993; Alexandre et al . 1996; Von Ohlen et al. 1997). Ci staining with a monoclonal antibody, 2A 1, that recognizes an epitope in the carboxyterminal half of $\mathrm{Ci}$, increases in response to $\mathrm{Hh}$, loss of Ptc activity, or loss of PKA activity in anterior imaginal disc cells, without any change in ci mRNA levels Johnson et al. 1995; Slusarski et al. 1995; Domínguez et al. 1996; Aza-Blanc et al. 1997). It has been shown recently that increased $2 \mathrm{~A} 1$ antibody staining due to $\mathrm{Hh}$ signal ing corresponds to a change in $\mathrm{C}$ i processing rather than total $\mathrm{Ci}$ protein concentration, as assumed previously (Aza-Blanc et al. 1997). Thus, full-length $\mathrm{Ci} \mathrm{(Ci-}$ 155) can be cleaved to an amino-terminal fragment ( $\mathrm{Ci}$ 75) that is not recognized by the "carboxy-terminal" an- 
tibody $2 \mathrm{~A} 1$, henceforth denoted as $\mathrm{Ci}-\mathrm{CT}$ antibody (AzaBlanc et al. 1997). Hh inhibits the cleavage of $\mathrm{Ci}-155$ and consequently leads to increased $\mathrm{Ci}-\mathrm{CT}$ antibody staining while total $\mathrm{Ci}$ protein concentration, assayed by an "amino-terminal" (Ci-NT) antibody remains constant (Aza-Blanc et al. 1997). Because increased Ci-CT antibody staining generally accompanies induction of $\mathrm{Hh}$ target genes, whether elicited by $\mathrm{Hh}$, PKA inhibition, or overexpression of a ci cDNA, it is thought that $\mathrm{Ci}-\mathrm{CT}$ antibody staining, corresponding to an increased concentration of full-length $\mathrm{Ci}$ protein, is a critical intermediate step in Hh target gene induction Johnson et al. 1995; Slusarski et al. 1995; Alexandre et al. 1996; Domínguez et al. 1996; Hepker et al. 1997). We have investigated $\mathrm{Hh}$ signaling in Drosophila embryos and find that PKA inhibition and $\mathrm{Hh}$ signaling increase $\mathrm{Ci}$ protein concentration detected by $\mathrm{Ci}-\mathrm{CT}$ antibody and induce target gene [wingless (wg) and patched (ptc)] expression, as observed previously in imaginal discs. We al so demonstrate novel signaling activities by which both PKA hyperactivity and $\mathrm{Hh}$ stimulate $\mathrm{wg}$ and ptc expression by a mechanism that requires the activities of Smo and $\mathrm{Ci}$ but does not involve any detectable changes in $\mathrm{Ci}$ protein concentration.

\section{Results}

PKA inhibition induces $\mathrm{Hh}$ target genes in embryos

In Drosophila embryos $\mathrm{Hh}$ is made in segmentally repeated stripes of engrailed (en)-expressing cells and is required to maintain expression of the target genes wg and ptc in stripes of immediately adjacent cells. wg is expressed anterior to each en stripe, whereas ptc is expressed on either side of en, forming two stripes per segment (Hidalgo and Ingham 1990) (Fig. 1a,b). ptc expression may serve to restrict diffusion of $\mathrm{Hh}$ (Chen and Struhl 1996) and moderate Hh signaling, whereas localized expression of wg is crucial initially to maintain en and hh expression and subsequently for ectodermal patterning within each parasegment (Peifer and Bejsovic 1992). U biquitous $\mathrm{Hh}$ expression can induce transcription of ptc in all cells that do not express en and that consequently express ci (Eaton and Kornberg 1990), whereas wg expression can be induced by $\mathrm{Hh}$ in a subset of those cells (Ingham 1993). Because the PKA catalytic subunit DCO is required for normal oogenesis and maternally supplied in sufficient quantities for embryogenesis (Lane and Kalderon 1993, 1994) we used a mutant regulatory subunit, $R^{*}$, expressed from a GAL4-responsive transgene (U AS- $R^{*}$ ) to reduce PKA activity in embryos ( $\mathrm{Li}$ et al. 1995). R* binds CAMP poorly and therefore maintains catal ytic subunit as inactive holoenzyme $\left(\mathrm{R}_{2}{ }_{2} \mathrm{DCO}_{2}\right)$ at physiological CAMP concentrations. Expression of $R^{*}$ ubiquitously in the ectoderm ("ubi$\mathrm{R}^{*}=\mathrm{E} 22 \mathrm{C}-\mathrm{GAL} 4+\mathrm{UAS}-\mathrm{R}^{*}$ ) or solely in non-en cells (using ptc-GAL4) caused an anterior expansion of wg expression (Fig. 1C) and expression of ptc in all non-en cells (Fig. 1d), without any accompanying change in en or hh expression (not shown). The alterations in wg, ptc, and ventral cuticle patterns (Fig. 5a,c, below) because of

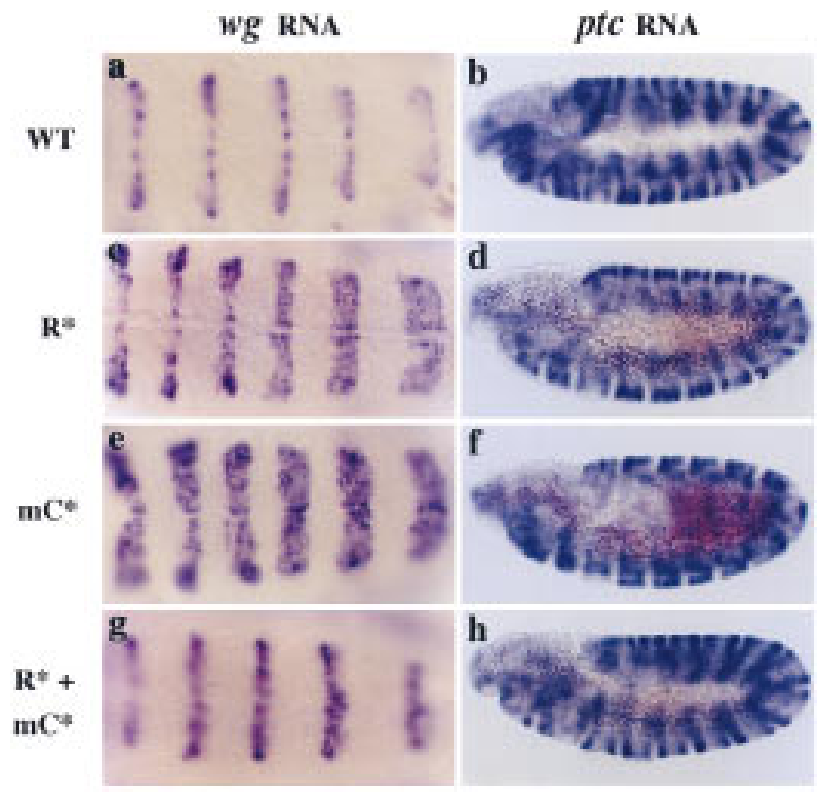

Figure 1. Increased or decreased PKA activity results in activation of $\mathrm{Hh}$ target genes wg and ptc. $(a, c, e, g)$ Ventral view of stage 11-12 embryos hybridized with wg RN A probe. Anterior is to the left. $(b, d, f, h)$ Lateral view of embryos hybridized with ptc RN A probe. Anterior is left and dorsal is up. $(a, b)$ Wild-type embryos showing the normal one-cell wide stripes of wg RNA and two thin stripes of ptc RNA in each segment of the ectoderm (clearest at the outer edge of the embryo in b). (c,d) ubi-R* embryos in which PKA is inhibited uniformly. wg RNA expression expands 1-4 cells toward the anterior beginning in late stage 11 embryos, and ptc RNA expression is expanded to all non-en-expressing cells. $(e, f)$ ubi-mC* embryos in which PKA activity is uniformly el evated. The expansions of wg RNA expression are more robust than for ubi- $\mathrm{R}^{*}$, reaching a width of 6-8 cells and are visible by early stage 11 . ptc RN A expression expands to all non-en cells. (g,h) ubi-R*/mC* embryos expressing both PKA transgenes have almost normal expression of wg and ptc, demonstrating the opposing activities of the two transgenes.

PKA inhibition in ubi-R* embryos resembled those induced by low-level ubiquitous expression of $\mathrm{Hh}$ but were less pronounced than those elicited by high levels of $\mathrm{Hh}$ or strong ptc mutations (Bejsovic and Wieschaus 1993; Ingham 1993; Tabata and Kornberg 1994). PKA inhibition restricted to en-expressing cells (using en-GAL4) had no effect on wg or ptc expression (not shown). Hence, inhibition of PKA can mimic the inductive effects of $\mathrm{Hh}$ in Hh-responsive cells of the embryo, just as in imaginal discs.

$\mathrm{Ci}$ protein, detected by monoclonal antibody $2 \mathrm{~A} 1$, is expressed in all non-en cells but is elevated in response to $\mathrm{Hh}$ at the borders of each broad segmental stripe (M otzny and Holmgren 1995) (Fig. 2b,h) and was induced to even higher levels throughout its normal expression domain by PKA inhibition in ubi-R* embryos (not shown). PKA inhibition in alternating segments of "alt$\mathrm{R}^{*}$ " [=paired (prd)-GAL4 +U AS-R*] embryos produced a cell-autonomous increase in $\mathrm{Ci}-\mathrm{CT}$ antibody staining (Fig. 2a,d) without affecting ci RNA levels (Fig. 2f) or 
Figure 2. Decreased but not increased PKA activity increases $\mathrm{Ci}-\mathrm{CT}$ antibody staining. (a) Antibody to $\beta$-gal actosi dase reveals the expression pattern of GAL4 attributable to the prd-GAL4 transgene in alt-lacZ (=prdGAL4 +UAS-lacZ) embryos. (b-h) Embryos stained with monoclonal antibody $2 A 1$, which detects an epitope in the carboxy-terminal half of the full-length $\mathrm{Ci}$ protein. (d) In alt-R* (=prd-GAL4 +UAS-R*) embryos there is a large increase in $\mathrm{Ci}-\mathrm{CT}$ antibody staining in roughly alternating segments corresponding to those cells that express the PKA inhibitor (as in a), but ci RNA (f) is uniformly expressed in all non-en cells, as in wild-type embryos. The extent of induction of $\mathrm{Ci}-\mathrm{CT}$ staining by PKA inhibition is better seen in Fig. 3. Here (d), it is underestimated because $C i$ staining is saturated to all ow direct comparison to other embryos. (e) In alt-mC* (=prd-GAL4 +UAS-mC*) embryos PKA hyperactivity does not alter Ci-CT antibody staining. (b,c,g,h) The focal plane differs from $\mathrm{d}$ and $\mathrm{e}$ to highlight accentuated $\mathrm{Ci}$ staining at the border of each band in wild-type embryos (b) that is absent from ubi-mC* embryos (c) (PKA hyperactivity) and also absent from embryos zygotically mutant for smo $\left(\mathrm{smo}^{11 \times 43}\right)(\mathrm{g})$ or $\left(\mathrm{hh}^{\mathrm{ts}}\right)(\mathrm{h})$.
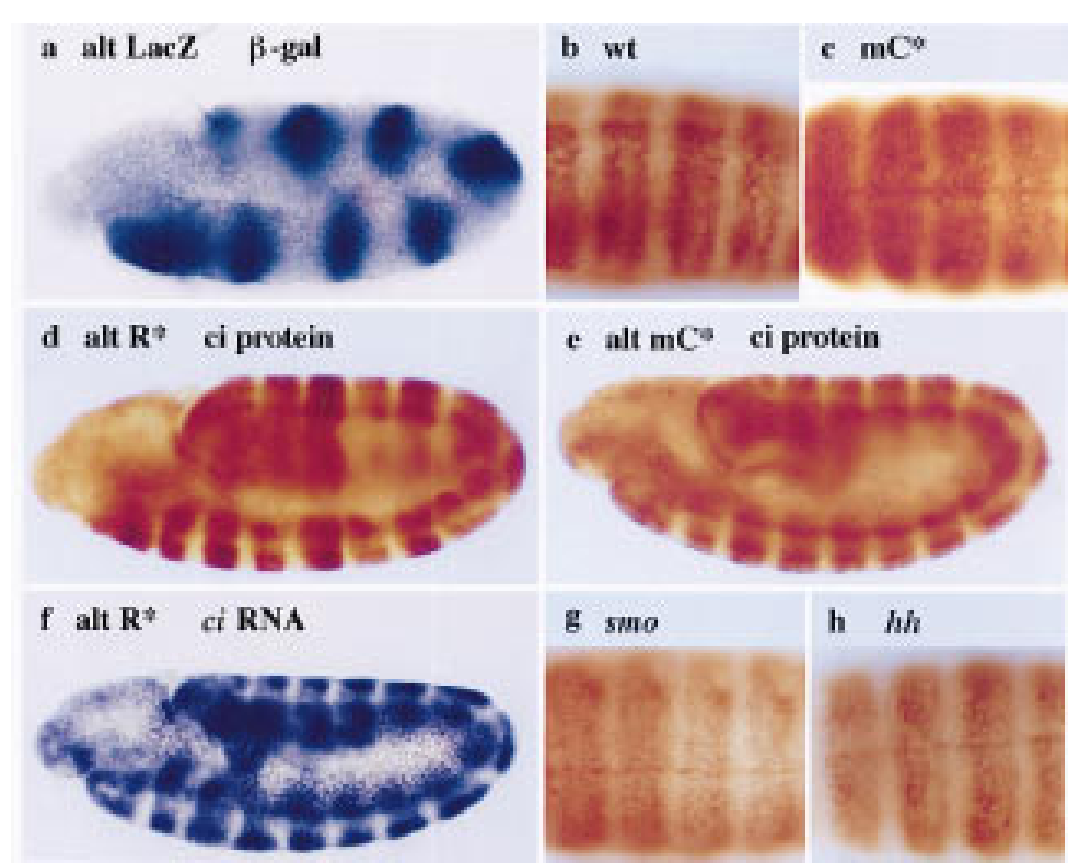

Ci-NT antibody staining (not shown). Thus, PKA inhibition appeared to have similar effects to $\mathrm{Hh}$ on $\mathrm{Ci}$ staining, presumably corresponding to an increased concentration of full-length $\mathrm{Ci}$ protein and could induce ectopic $\mathrm{Hh}$ target gene expression in the embryo. However, PKA inhibition induced higher levels of $\mathrm{Ci}-\mathrm{CT}$ staining than Hh (Figs. 2, b,d, and h; and 3c) but was less potent than $\mathrm{Hh}$ at inducing wg and ptc expression in ubi-R* embryos (Fig. 1c,d), and especially in alt-R* embryos (Fig. 3a,b), where only a slight expansion of ptc expression is seen and wg expression appears normal. This discrepancy provided the first hint that PKA or $\mathrm{Hh}$ might have additional functions that do not affect $\mathrm{Ci}$ protein levels.

$\mathrm{Hh}$ and $\mathrm{Hh}$ pathway components can induce wg expression independent of $\mathrm{Ci}$ protein levels

To test for additional functions of $\mathrm{Hh}$ we introduced $\mathrm{Hh}$ pathway mutations into alt-R* embryos, in an attempt to circumvent the need for $\mathrm{Hh}$ to al ter $\mathrm{Ci}$ protein levels. In alt-R* embryos the induction of high levels of $\mathrm{Ci}-\mathrm{CT}$ antibody staining (brown, Fig. 3c) anterior to the oddnumbered En stripes (blue, Fig. 3c) by PKA inhibition was not affected by hh or smo mutations (Fig. 3f,i). These embryos were double-stained with En antibody to identify the hh and smo mutant embryos among their siblings and were deliberately understained to show that the levels of immunoreactive $\mathrm{Ci}$ were not affected by $\mathrm{hh}$ or smo mutations (cf. Figs. $3 \mathrm{c}$ and $3 f$ and i). In these understained embryos normal levels of $\mathrm{Ci}$ anterior to even-numbered En stripes are barely visible. Although they did not alter the effects of PKA inhibition on $\mathrm{Ci}$ staining, hh and smo mutations each eliminated expres- sion of wg in alt-R* embryos, even in those cells with high levels of $\mathrm{Ci}-\mathrm{CT}$ antibody staining (Fig. 3a,d,g). Hence, $\mathrm{Hh}$ and Smo each provides an essential contribution to wg expression without detectably altering $\mathrm{Ci}$ protein levels, indicating a bifurcating pathway of $\mathrm{Hh}$ signaling downstream of Smo (Fig. 6, below). This is particularly clear in alt-R* embryos lacking Smo activity, in which adjacent wg stripes decay at identical rates despite a huge difference in $\mathrm{Ci}-\mathrm{CT}$ antibody staining be tween adjacent segments (Fig. 3g,i).

Expression of ptc RNA in response to PKA inhibition in alternating segments was still observed in hh mutants (Fig. 3e), suggesting a greater dependence of wg expression than ptc expression on the pathway of $\mathrm{Hh}$ signaling that does not alter $\mathrm{Ci}$ levels (Fig. 6, A, open arrow, below). In contrast, smo mutations eliminated expression of ptc in response to PKA inhibition (Fig. 3h), suggesting that Smo has a significant basal activity in the absence of Hh (Fig. 6, A, solid arrow, below). Expression of wg and ptc was not affected in alt-R* or ubi-R* embryos by loss of one active ci allele but was eliminated by complete loss of $\mathrm{Ci}$ activity (not shown).

Increased PKA activity also induces $\mathrm{Hh}$ target genes in embryos

A constitutively active mouse PKA catalytic subunit transgene, $\mathrm{mC}^{*}$, was shown previously to oppose the el evated expression of Ptc protein in response to $\mathrm{Hh}$ in imaginal discs (Li et al. 1995). In stark contrast, expression of $\mathrm{mC}^{*}$ in embryos ubiquitously (ubi-mC*) or under the influence of ptc-GA L4, but not en-GAL4, caused ectopic expression of wg and ptc (Fig. 1e,f) without alter- 

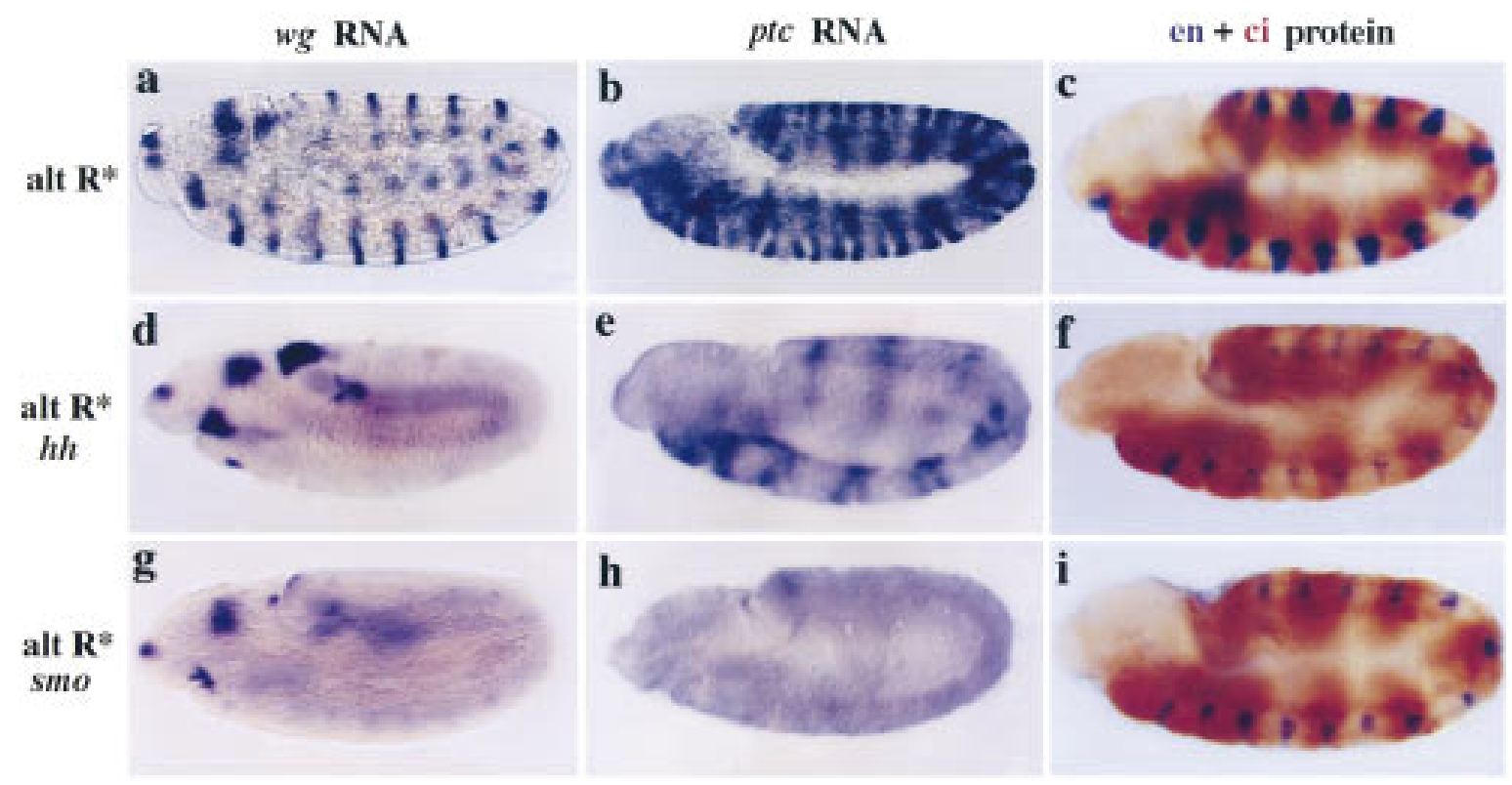

Figure 3. Hh and Smo can affect wg and ptc expression without al tering Ci protein levels. Stage 10-12 embryos were hybridized with wg RNA $(a, d, g)$, ptc RNA (b,e,h), or double-stained with Ci-CT antibody (brown) and En antibody (blue) (c,f,i). In alt-R* embryos wg expression is close to wild type (a), ptc RNA is slightly expanded (b), but Ci-CT antibody staining is very high in cells of alternating segments that express the PKA inhibitor (c) (as in Fig. 2d). These embryos were stained more lightly for Ci than those in Fig. 2 so that normal levels of $\mathrm{Ci}$ protein are barely visible. (d-f) alt-R* embryos al so mutant for hh ( $\mathrm{hh}^{\text {ts2 }}$ at $29^{\circ} \mathrm{C}$ ) lose wg (d) and En (f) expression in all segments by stage 10 but the levels of $\mathrm{Ci}-\mathrm{CT}$ antibody staining remain very high (f) and ptc RN A is still expressed in cells of al ternating segments that express the PKA inhibitor (e). ( $\mathrm{g}-\mathrm{i}$ ) alt-R* embryos lacking maternal and zygotic smo gene activity (smo ${ }^{11 \times 43}$ ) Iose wg RNA (g), ptc RNA (h), and En expression (i) in all segments by stage 10 without alteration of high Ci-CT antibody staining in al ternating segments (i). alt-R* embryos lacking only zygotic smo have a similar phenotype, in which wg, ptc, and En expression decay at the same rate in adjacent segments and are substantially lost by the end of stage 11 . wg and ptc expression al so decay equal ly in adjacent segments of alt-R* embryos lacking ci activity [Df(4)M $62 \mathrm{f}^{*}$ or $\mathrm{Ci}^{\mathrm{DR}}{ }^{\mathrm{D}}$; not shown].

ing en or hh expression (not shown). The anterior expansion of wg stripes was more robust in ubi-mC* than ubi-R* embryos but was also only apparent after stage 11 and associated with ventral cuticles resembling those due to low-level ectopic $\mathrm{Hh}$, rather than strong ptc mutations (Fig. 5d, below).

In embryos expressing both $\mathrm{mC}^{*}$ and $\mathrm{R}^{*}$ (ubi-mC*/ $R^{*}$ ) wg and ptc expression patterns were close to wild type (Fig. 1g,h), as was $\mathrm{Ci}-\mathrm{CT}$ antibody staining (not shown). This confirmed the opposing actions of the two transgenes on PKA activity, as was also verified biochemical ly (Li et al. 1995). In contrast to all other documented manipulations of $\mathrm{Hh}$ pathway components, PKA hyperactivity in alt-mC* embryos caused ectopic expression of wg and ptc (Fig. 4a,b) without any increase in the level of ci RN A (not shown) or Ci protein detected by $\mathrm{Ci}-\mathrm{CT}$ antibody (Fig. 2e) or Ci-NT antibody (not shown). PKA must therefore have a second target rel evant to $\mathrm{Hh}$ signaling that does not influence $\mathrm{Ci}$ protein levels.

Although PKA hyperactivity did not discernibly affect $\mathrm{Ci}$ staining in cells in the center of each $\mathrm{C} i$ stripe that expressed wg and ptc ectopically, it did suppress the elevation of $\mathrm{Ci}-\mathrm{CT}$ antibody staining normally elicited by $\mathrm{Hh}$ at the borders of each $\mathrm{Ci}$ stripe (Fig. 2C). Thus, in the absence of $\mathrm{Hh}, \mathrm{Ci}-\mathrm{CT}$ staining responds dramatically to reductions in PKA activity (Figs. 2d and $3 c$ ) but is insensitive to increased PKA activity.
Responses to elevated PKA activity require Smo and $\mathrm{Ci}$ but not $\mathrm{Hh}$

To explore the positive actions of PKA on $\mathrm{Hh}$ target gene expression further we examined the effects of various $\mathrm{Hh}$ pathway mutations. Loss of $\mathrm{Hh}$ activity did not impair the ectopic induction of $\mathrm{wg}$ and ptc by elevated PKA activity in alternating segments of alt-mC* embryos (Fig. 4a-d). In contrast, Smo activity was required to observe any response of wg or ptc to el evated PKA even in embryos deficient only for zygotic smo (Fig. 4e,f). The essential activity of Smo, as opposed to $\mathrm{Hh}$, cannot be explained by effects on Ci protein levels, as zygotic smo mutations and hh mutations have equival ent effects, reducing $\mathrm{Ci}-\mathrm{CT}$ antibody staining only at the borders of each $\mathrm{Ci}$ stripe (Fig. 2b,g,h). The absolute requi rement for Smo to observe transcriptional induction by PKA hyperactivity is consistent with two mechanisms. Either PKA acts on Smo, directly or indirectly, perhaps to uncouple it from the inhibitory influence of Ptc (Fig. 6, B and A, below) or, alternatively, Smo has $\mathrm{Hh}$-independent activity that acts in parallel with PKA to stimulate wg and ptc expression (Fig. 6, C and A, below). Although the response to PKA hyperactivity did not involve changes in Ci staining it did absolutely require $\mathrm{Ci}$ activity (Fig. $4 \mathrm{~g}$,h), indicating a mechanism that either involves modification of $\mathrm{Ci}$ or requires $\mathrm{Ci}$ to act as a cofactor for wg and ptc expression. 


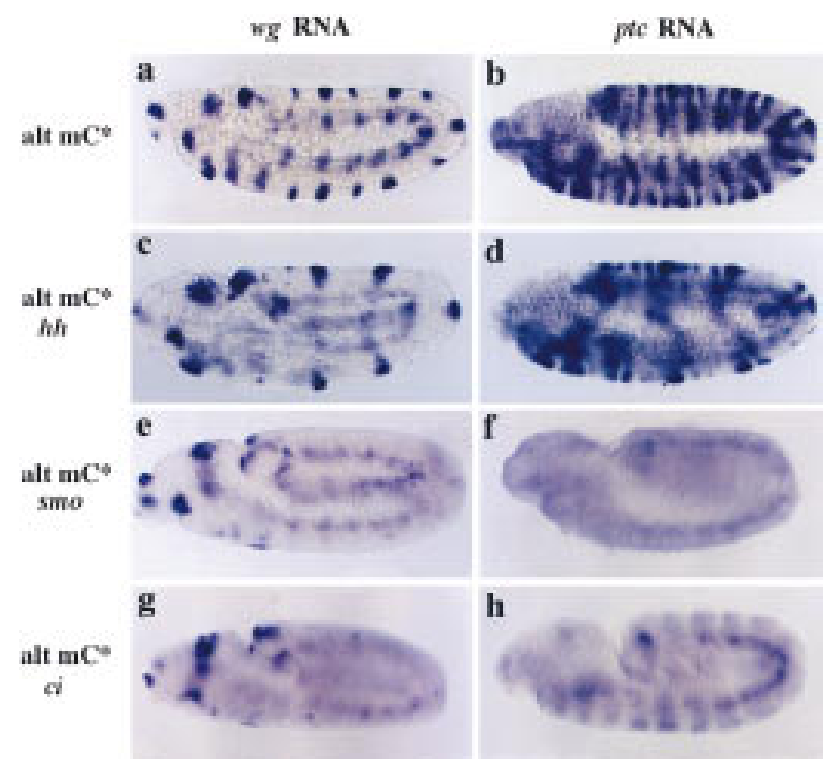

Figure 4. Induction of $\mathrm{wg}$ and ptc by elevated PKA activity requires Smo and $\mathrm{Ci}$ but not $\mathrm{Hh}$. $(\mathrm{a}, \mathrm{b})$ alt-mC* $(=$ prdGAL4 +U AS-mC*) embryos show expanded wg RNA (a) and ptc RNA (b) expression in the even parasegments. (c,d) alt-mC* embryos carrying the $h^{\text {ts2 }}$ mutation lose wild-type stripes of wg RN A (c) and ptc RN A (d) in odd-numbered parasegments by stage 10, but expanded wg and ptc expression in cells with increased PKA activity is unaffected by the hh mutation. In altmC* embryos that also lack maternal and zygotic smo $\left(\mathrm{smo}^{11 \times 43}\right)(\mathrm{e}, \mathrm{f})$ or zygotic ci activity [Df(4)M62f or $\left.\mathrm{Ci}^{\mathrm{DR} 50}\right](\mathrm{g}, \mathrm{h})$, wg RNA $(e, g)$, and ptc RN A (f,h) expression are lost in all parasegments by stage 10, indicating that the responses to el evated PKA activity require smo and ci activity. In alt-mC* embryos deficient only for zygotic smo (not shown), wg and ptc RNA expression decay at equal rates in adjacent segments and are lost by the end of stage 11 .

Hh signaling does not require CAMP-mediated regulation of PKA activity

The structure of Smo has invited speculation that it couples to a $G$ protein and might therefore regulate cAM P concentration (Alcedo et al. 1996; van den Heuvel and Ingham 1996). To examine this idea we tested whether low-level expression of $\mathrm{mC} *$ from an actin-5C promoter could substitute for Drosophila PKA catalytic subunit DCO activity in embryos. The mC* catalytic subunit binds poorly to regulatory subunit and is therefore active regardless of CAMP concentration (Orellana and McKnight 1992). Expression of $\mathrm{mC}^{*}$ in the female germ line rescued the functions of DCO in oogenesis and allowed a small proportion of eggs to be fertilized and to develop (Y. Zhang, W. Li, and D. Kalderon, unpubl.). $M$ any of these embryos hatched even if maternally and zygotically null for DCO and exhibited ventral cuticle patterns similar to wild type (Fig. 5a,b), i mplying normal $\mathrm{Hh}$ signaling. Hence, as observed previously in imaginal discs (Jiang and Struhl 1995; Li et al. 1995), neither transcriptional nor CAMP-dependent regulation of PKA activity appear to be essential for $\mathrm{Hh}$ signaling.

\section{Discussion}

Previous models of Hh signaling in Drosophila have emphasized changes in the concentration of $\mathrm{Ci}$ proteins, detected by $\mathrm{Ci}-\mathrm{CT}$ antibody, as the goal of signal transduction. Also, the antagonistic effects of PKA on $\mathrm{Hh}$ target gene expression and involvement of the serpentine transmembrane protein Smo, predicted to couple to a G-protein, have sometimes been rationalized as indicative of CAMP acting as a key intermediate. We have shown that regulation of $\mathrm{Ci}$ protein levels is a common focus for the antagonistic actions of $\mathrm{Hh}$ and PKA in Drosophila embryos but have also obtained evidence for novel positive actions of both PKA and $\mathrm{Hh}$ in inducing $\mathrm{Hh}$ target genes without affecting $\mathrm{Ci}$ protein levels. In addition, we have shown that, as in imaginal discs, regulation of PKA activity by CAM $\mathrm{P}$ is not essential to $\mathrm{Hh}$ signal transduction in embryos.

Repression of $\mathrm{Hh}$ target genes by PKA; possible targets

PKA inhibition in Drosophila embryos induced ectopic expression of the $\mathrm{Hh}$ target genes wg and ptc (Fig. 1) and was accompanied by increased Ci-CT antibody staining, without affecting $\mathrm{Ci}-\mathrm{NT}$ antibody staining or ci mRN A levels (Fig. 2). Because $\mathrm{Hh}$ has similar effects and has been shown to inhibit the cleavage of full-length $\mathrm{Ci}$ protein (Ci-155), it is very likely that PKA inhibition also reduces cleavage of $\mathrm{Ci}-155$. This hypothesis must be tested directly in the future but is consistent with our observation that increased PKA activity suppresses the

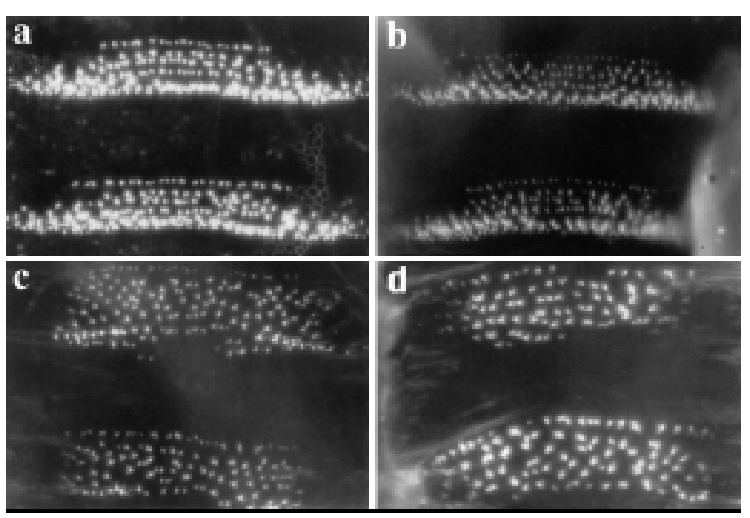

Figure 5. Regulation of PKA by CAMP is not essential for $\mathrm{Hh}$ signaling. Ventral cuticles (fifth and sixth abdominal segments) of wild-type larvae (a) and larvae that expressed mC* from an actin-5C promoter but were maternally and zygotically null for DCO (b) showed the same trapezoidal pattern, number, and spacing of rows, indicating normal $\mathrm{Hh}$ signaling. In ubi-R* larvae (PKA inhibition) (c) and ubi-mC* Iarvae (PKA hyperactivity) (d) the wide posterior rows of each segment are replaced by narrower and often incomplete rows of different denticle morphology and polarity to give a rectangular denticle pattern characteristic of embryos expressing $\mathrm{Hh}$ ubiquitously at low levels. They do not show a duplication of the most anterior row in place of the posterior rows that is characteristic of ptc mutations. 
effects of $\mathrm{Hh}$ on $\mathrm{Ci}-\mathrm{CT}$ staining (Fig. 2c). It is believed that $\mathrm{Ci}-155$, or an uncharacterized derivative, acts as a transcriptional activator, whereas $\mathrm{Ci}-75$ is believed to act as a transcriptional repressor (Aza-Blanc et al. 1997) so that an increase in the proportion of $\mathrm{Ci}$ protein that is full length is expected to stimulate $\mathrm{Hh}$ target gene expression. Most likely, therefore, the altered levels of $\mathrm{Ci}$ proteins detected by $\mathrm{Ci}-\mathrm{CT}$ antibody are responsible for the ectopic expression of wg and ptc induced by PKA inhibition in embryos. The effect of PKA on Ci protein levels is unchanged in hh or smo mutant embryos and might therefore be mediated by direct phosphorylation of $\mathrm{Ci}$, which includes several consensus PKA sites (Orenic et al. 1990).

Positive action of PKA in $\mathrm{Hh}$ signaling; possible PKA targets

Previously PKA has been shown only to repress $\mathrm{Hh}$ target gene expressi on in Drosophila and in vertebrates (Fan et al. 1995; Kalderon 1995; Concordet et al . 1996; Epstein et al. 1996; Hammerschmidt et al. 1996; Ungar and Moon 1996). We have demonstrated that PKA can also stimulate $\mathrm{Hh}$ target gene expression in Drosophila embryos by using an al tered mouse catalytic subunit, $\mathrm{mC} *$, as a source of hyperactive PKA. The response to $\mathrm{mC}^{*}$ was suppressed by $\mathrm{R}^{*}$, which can inhibit endogenous Drosophila PKA but not $\mathrm{mC}^{*}$, implying that Drosophila PKA can and normally does phosphorylate the $\mathrm{mC}^{*}$ substrate that promotes $\mathrm{Hh}$ target gene expression. Because we can reduce but not eliminate PKA activity from early embryos we do not know if the stimulation of $\mathrm{Hh}$ target gene expression by PKA is essential in wild-type embryos. The mechanism by which PKA hyperactivity induces $\mathrm{Hh}$ target genes does not involve discernible changes in $\mathrm{Ci}$ protein levels and is therefore clearly different from the cellular response to reducing PKA activity.

The induction of wg and ptc expression by PKA hyperactivity was eliminated by smo or ci mutations but not by hh mutations. Hence, Smo and $\mathrm{Ci}$ but not $\mathrm{Hh}$ are potential obligatory mediators of the positive effects of PKA on $\mathrm{Hh}$ target genes. It is possible that PKA acts directly on Smo, rendering it fully or partially active even in the absence of $\mathrm{Hh}$ (Fig. 6, B). Smo contains several potential PKA phosphorylation sites (Alcedo et al. 1996; van den Heuvel and Ingham 1996), and there is considerable evidence that phosphorylation can al ter the activity of $G$ protein-coupled receptors (Freedman and Lefkowitz 1996). Also, in this scenario a single mechanism downstream of Smo (Fig. 6, A) would account for the actions of both PKA and $\mathrm{Hh}$ that stimulate $\mathrm{Hh}$ target gene expression without altering $\mathrm{Ci}$ protein levels. Alternatively, PKA and Smo may contribute independently to $\mathrm{Hh}$ target gene expression (Fig. 6, C and A). In this case, $\mathrm{Ci}$ could be a relevant PKA target. It is even possible that both positive and negative effects of PKA on wg and ptc expression are mediated by phosphorylation of $\mathrm{Ci}$, so long as distinct sites of different affinity and regulatory consequence are used.

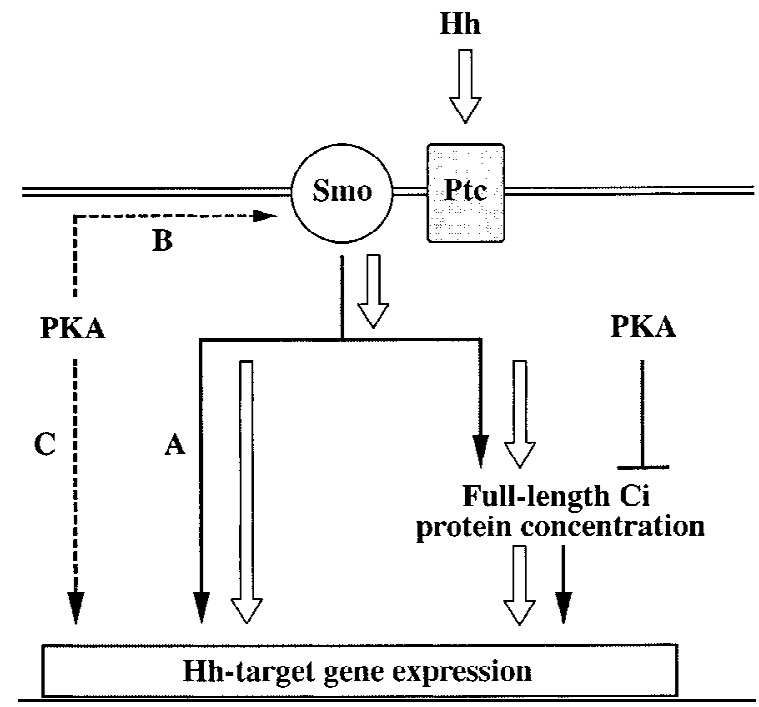

Figure 6. Hh signal transduction in Drosophila embryos. (Right) The familiar antagonistic effects of $\mathrm{Hh}$ and PKA on $\mathrm{Ci}$ protein levels detectable by monoclonal antibody $2 \mathrm{~A} 1$, which we assume here to reflect the concentration of full-length $\mathrm{Ci}$ protein. High levels of full-length Ci protein are normally associated with activation of $\mathrm{Hh}$ target genes. (Left) Novel additional actions of $\mathrm{Hh}, \mathrm{Smo}$, and PKA that stimulate $\mathrm{Hh}$ target gene expression in embryos without discernibly altering the concentration of $\mathrm{C} i$ proteins. Induction of $\mathrm{wg}$ and ptc expression by PKA hyperactivity required smo but not hh, implying that Smo either mediates the response to PKA ( $B$ and $A$ ) or has a basal activity that acts in concert with PKA ( $C$ and $A$ ). In embryos with high levels of $\mathrm{Ci}-\mathrm{CT}$ antibody staining attributable to PKA inhibition, Smo activity was required to activate wg and ptc expression, whereas $\mathrm{Hh}$ activity was required only for wg expression. This suggests that Smo has a basal ( $\mathrm{Hh}$-independent) activity sufficient to induce ptc expression ( $A$, solid arrow) that can be enhanced by $\mathrm{Hh}$ ( $\mathrm{A}$, open arrow) to stimulate wg expression, in each case without affecting $\mathrm{Ci}$ protein concentration. Thus, basal activities of PKA and Smo (solid vertical lines) poise the cell to respond by two distinct mechanisms to $\mathrm{Hh}$ (open arrows).

\section{Dual actions of PKA}

Two PKA targets with opposing actions on $\mathrm{Hh}$ target gene expression (Fig. 6) can account for the initially surprising observation that both PKA inhibition and PKA hyperactivity induced $w g$ and ptc expression in embryos. The negative target, relevant to regulating $\mathrm{Ci}$ protein levels, was sensitive al most excl usi vely to reduction of PKA activity (Fig. 2d,e). Thus, only the positive target (Fig. 6, left) responds to PKA hyperactivity, leading to ectopic expression of wg and ptc in ubi-mC* (Fig. 1e,f) and alt$\mathrm{mC}^{*}$ embryos (Fig. 4a,b). When PKA activity was decreased in ubi-R* embryos the conflicting influences of a large increase in $\mathrm{Ci}-\mathrm{CT}$ antibody staining, presumably reflecting full-length $\mathrm{Ci}$ protein concentration, and a diminished contribution of the positive PKA target (of unknown magnitude) combined to produce a more modest ectopic induction of $\mathrm{wg}$ and ptc (Fig. 1c,d). In alt-R* embryos the combination of these two influences pro- 
duced only a slight induction of ectopic ptc expression and no ectopic induction of wg expression (Fig. 3a,b).

Despite the potent effects of PKA on $\mathrm{Hh}$ target gene expression, changes in CAMP concentration cannot account for $\mathrm{Hh}$ signaling. First, in embryos, as in imaginal discs, replacement of the major Drosophila PKA cataIytic subunit DCO with $\mathrm{mC} *$, which is insensitive to CAMP, did not prevent $\mathrm{Hh}$ signaling Jiang and Struhl 1995; Li et al. 1995). Second, neither inhibition nor activation of PKA in embryos stimulated $\mathrm{Ci}-\mathrm{CT}$ antibody staining and wg RN A in the same proportion as normally induced by $\mathrm{Hh}$. These observations do not exclude the possibility that modulation of PKA activity might make some contribution to $\mathrm{Hh}$ signaling, but they are not consistent with a central role for CAM P as a mediator of $\mathrm{Hh}$ signaling.

\section{Dual actions of Hh signaling pathway}

Prior to this study the only significant indicator that $\mathrm{Hh}$ signaling in Drosophila may involve more than simply regulating $\mathrm{Ci}$ protein levels were phenotypes attributable to fu mutations in which $\mathrm{Hh}$ target gene expression was attenuated or el iminated despite extremely high levels of Ci-CT antibody staining (M otzny and Holmgren 1995; Slusarski et al. 1995). Whether this activity of Fu reflected an activity of $\mathrm{Hh}$ was unclear, however, as Fu, although phosphorylated in response to $\mathrm{Hh}$ (Thérond et al. 1996b), is not required for $\mathrm{Hh}$ signaling in the absence of Su(fu) (Thérond et al. 1996a). In this study, we used PKA inhibition as a means of substituting for the effect of $\mathrm{Hh}$ on $\mathrm{Ci}$ protein processing. The increase in $\mathrm{Ci}-\mathrm{CT}$ antibody staining because of PKA inhibition was at least as great as induced during normal $\mathrm{Hh}$ signaling and was not accompanied by any change in $\mathrm{Ci}-\mathrm{NT}$ antibody staining, suggesting that PKA inhibition does phenocopy the effects of $\mathrm{Hh}$ on $\mathrm{Ci}$ cleavage. Under these circumstances, we found that both $\mathrm{Hh}$ and Smo were essential to maintain wg expression despite unchanged $\mathrm{Ci}$ staining. Thus, both $\mathrm{Hh}$ and Smo, an established mediator of $\mathrm{Hh}$ signals, provided a positive input to wg expression that was independent of detectable changes in $\mathrm{Ci}$ protein levels (Fig. 6A).

It was shown recently that in embryos with normal PKA activity wg can be induced by overexpression of a ci CDNA even in the absence of $\mathrm{Hh}$ activity (Alexandre et al. 1996). It is likely that we observed stricter requirements for Hh activity to induce wg expression because we simultaneously reduced the positive input from PKA toward $\mathrm{Hh}$ target gene expression (Fig. 6, B or C).

Functional implications of dual actions of PKA and $\mathrm{Hh}$

We believe that the novel mechanisms depicted in Figure 6 , namely a positive action of PKA and an action of $\mathrm{Hh}$ that is not related to alteration of $\mathrm{Ci}$ protein levels, are also operative in imaginal discs. In wing discs most patterning responses to $\mathrm{Hh}$ and the expression of ptc reveal only an antagonistic effect of PKA (Jiang and Struhl 1995; Lepage et al. 1995; Li et al. 1995; Pan and Rubin
1995). However, we have found that formation of nonneuronal bristles at the wing margin in response to either $\mathrm{Hh}$ or loss of ptc function requires PKA activity (J.T. Ohlmeyer, W. Li, and D. Kalderon, unpubl.), suggesting conservation of the positive function of PKA in $\mathrm{Hh}$ signaling. A similar defect in patterning of wing margin bristles is seen as a consequence of reduced Fu activity even though $\mathrm{Ci}-\mathrm{CT}$ antibody staining is high in fu mutant cells responding to $\mathrm{Hh}$ (Slusarski et al. 1995; Sánchez-Herrero et al . 1996; J.T. Ohl meyer, W. Li, and D. Kal deron, unpubl.). These observations suggest that the novel activities of $\mathrm{Hh}$ and PKA that we have described are general features of $\mathrm{Hh}$ signaling in Drosophila that are particularly obvious in embryos. It is possible that in vertebrates, as in Drosophila imaginal discs, a positive contribution of PKA to a subset of $\mathrm{Hh}$ responses is also present but not easily discerned in the background of the more prominent repressive effect of PKA on $\mathrm{Hh}$ target gene expression (Fan et al. 1995; Concordet et al. 1996; Epstein et al. 1996; Hammerschmidt et al. 1996; Ungar and Moon 1996).

The target specificity of the two arms of $\mathrm{Hh}$ signaling (Fig. 6) need not be identical even though the common requirement for $\mathrm{Ci}$ activity suggests that a $\mathrm{Ci}$-binding site will al ways be present in target genes. In embryos we observed a differential dependence of wg and ptc expression on the novel arm of $\mathrm{Hh}$ signaling (Fig. 6A) by assaying the response to $\mathrm{Hh}$ at constant $\mathrm{Ci}$ protein levels (Fig. $3 e, h)$. Similarly, in imaginal discs fu mutations allow $\mathrm{Hh}$-dependent changes in $\mathrm{Ci}$ protein levels but have a greater inhibitory effect on the induction of anterior en expression than on the induction of decapentaplegic (dpp) expression by Hh (Slusarski et al. 1995; SánchezHerrero et al. 1996; J.T. Ohlmeyer, W. Li, and D. Kalderon, unpubl.). Also, productive signaling in each branch of the pathway might require a different threshold concentration of $\mathrm{Hh}$. Hence, dual arms of $\mathrm{Hh}$ signaling provide a mechanism that may underl ie the ability of $\mathrm{Hh}$ family molecules to produce different transcriptional responses in similar cells according to $\mathrm{Hh}$ concentration (Heemskerk and DiN ardo 1994; Roelink et al. 1995; Ericson et al. 1996; Struhl et al. 1997) or the presence of other signaling molecules (Hooper 1994; Yoffe et al. 1995).

\section{Materials and methods}

Fly stocks and crosses

Flies homozygous for U AS-R* and U AS-mC* transgenes (Li et al. 1995) were crossed to flies homozygous for the "E22C" enhancer-trap line (A. Brand and N. Perrimon, unpubl.) or a prdGAL4 transgene, "RG 1" (Y offe et al. 1995) to generate embryos with reduced or excess PKA activity, respectively (confirmed by measurements in extracts in the presence of $1 \mu \mathrm{M}$ CAMP as described previously ( $\mathrm{Li}$ et al. 1995). In all cases, embryos were collected for $3 \mathrm{hr}$ at $25^{\circ} \mathrm{C}$ and incubated at $29^{\circ} \mathrm{C}$ for an additional $5 \mathrm{hr}$ to obtain stage 10-13 embryos and to maximize expression of GAL4-responsive transgenes. hh mutations were introduced by crossing U AS-R* or UAS-mC*; hh ${ }^{\text {ts2 }} /$ TM $6 \mathrm{~B}$ flies to $h^{\text {ts2 }}$ RG1/TM6B flies. Homozygous $h^{\text {ts2 }}$ progeny were identified by loss of wg, ptc, or En (in double stains with $\mathrm{Ci}$ ) expres- 
sion in alternate segments and were found in the expected proportions. $\mathrm{hh}^{\text {ts2 }}$ is a hypomorph reported to have no discernible activity at $29^{\circ} \mathrm{C}$ (M a et al. 1993). Embryos zygotically mutant for $\mathrm{Smo}^{11 \times 43}$ were similarly identified among progeny of the crosses $\mathrm{Smo}^{11 \times 43}$ UAS-mC*/CyO or $\mathrm{smo}^{11 \times 43} / \mathrm{CyO}$; UAS-R*/ UAS-R* $\times \mathrm{Smo}^{11 \times 43} / \mathrm{CyO}$; RG1/RG1 (or E22C smo ${ }^{11 \times 43} / \mathrm{CyO}$ ). Embryos also maternally deficient for smo were generated by the FLP-dominant female sterile (DFS) technique (Chou et al. 1993), inducing germ-line clones in females that were $\mathrm{smo}^{11 \times 43}$ FRT40A/P[OVo ${ }^{\mathrm{D}}$ ] FRT40A; UAS-R*/+ or $\mathrm{smo}^{11 \times 43}$ FRT40A UAS-mC*/P[ovo ${ }^{\mathrm{D} 1}$ ] FRT40A and crossing to $\mathrm{smo}^{11 \times 43} / \mathrm{CyO}$; RG1/RG1 males. smo ${ }^{11 \times 43}$ is amorphic (van den Heuvel and Ingham 1996). The effects of ci mutations were tested by crosses between UAS-R*/UAS-R* or UAS-mC*/UAS-mC*; $\mathrm{Df}(4) \mathrm{M} 62 \mathrm{f} / \mathrm{ey}^{\mathrm{D}}$ or $\mathrm{Ci}^{\mathrm{DR} 50} / \mathrm{M} 63 \mathrm{a}$ females and E22C/E22C or RG1/RG1; Df(4)M62f/ey ${ }^{\mathrm{D}}$ or ci ${ }^{\mathrm{DR} 50} / \mathrm{M} 63 \mathrm{a}$ males. M62f is a deficiency that is null for $\mathrm{Ci}$ and $\mathrm{ci}^{\mathrm{DR} 50}$ is a loss-of-function mutation (Slusarski et al. 1995); identical results were found with each allele. DCO null germ-line clones (Lane and Kalderon 1994) were generated at the same time as activating $\mathrm{mC} *$ expression from an actin-5C promoter by inducing FLP recombinase in females that were $\mathrm{DCO}^{\mathrm{H} 2}$ FRT40A actin $<\mathrm{y}^{+}<\mathrm{mC}^{*}$ / $\mathrm{P}\left[\right.$ ovo $\left.^{\mathrm{D} 1}\right]$ FRT40A (where <denotes an FRT) to produce the germ-line genotype $\mathrm{DCO}^{\mathrm{H} 2}$ FRT40A actin $<\mathrm{mC}^{*} / \mathrm{DCO}^{\mathrm{H} 2}$ FRT40A and crossing to $\left.\mathrm{Df}(2 \mathrm{~L}) \gamma 15 / \mathrm{P}^{+} \mathrm{y}^{+}\right] \mathrm{CyO}$ males heterozygous for a DCO deficiency. Cuticles of hatching $y^{-}$larvae were examined.

\section{Examination of embryos}

In situ hybridizations on whole-mount embryos used digoxigenin-labeled RN A probes synthesized by T7 RNA polymerase for wg, plasmid wgPx4 (J. Mohler, Barnard College, N ew York, NY) cut by Pstl; ptc, plasmid Dra2N ptc (S. DiN ardo, Rockefeller University, New York, NY) cut by Hincll; hh, plasmid 4.1/ 8B\#6 (J. Mohler) cut by Ndel; and ci, plasmid pGEM7Zci (R. Holmgren, Northwestern University, Evanston, IL) cut by BamHI and Xbal. Antibody stainings were performed using monoclonal En/Inv antibody [4D9; (Patel et al. 1989)], monoclonal Ci -CT antibody [2A 1; (Motzny and Holmgren 1995)], polyclonal Ci-NT antibody (Aza-Blanc et al. 1997), or polyclonal anti- $\beta$-galactosidase (Cappel). Larval cuticles were prepared by a modification (S. DiN ardo) of a published procedure (Heemskerk and DiN ardo 1994).

\section{Acknowledgments}

We are very grateful to Kelli Chung for hel $p$ with experiments; Steve DiN ardo, Corey Goodman, Bob Holmgren, Tom Kornberg, Armen M anoukian, Jim M ohler, and N orbert Perrimon for generously supplying key reagents; Steve DiN ardo, Tom Kornberg, and Armen Manoukian for communication of results and discussion; and Nick Baker, Judy Hull, Jim Mohler, Mary Ann Price, Andrew Tomlinson, and $Y$ an Zhang for comments on the manuscript. This work was fully supported by $\mathrm{N}$ ational Institutes of Health $(\mathrm{NIH})$ grant GM 41815 to D.K. and an NIH predoctoral training grant to J.T.O.

The publication costs of this article were defrayed in part by payment of page charges. This article must therefore be hereby marked "advertisement" in accordance with 18 USC section 1734 solely to indicate this fact.

\section{References}

Alcedo, J., M. Ayzenzon, T. Von Ohlen, M. Noll, and J.E.
Hooper. 1996. The Drosophila smoothened gene encodes a seven-pass membrane protein, a putative receptor for the hedgehog signal. Cell 86: 221-232.

Alexandre, C., A. Jacinto and P.W. Ingham. 1996. Transcriptional activation of hedgehog target genes in Drosophila is mediated directly by the Cubitus interruptus protein, a member of the GLI family of zinc finger DNA-binding proteins. Genes \& Dev. 10: 2003-2013.

Aza-Blanc, P., F.-A. Ramirez-Weber, M.-P. Laget, C. Schwartz, and T.B. Kornberg. 1997. Proteolysis that can be inhibited by Hedgehog targets Cubitus interruptus protein to the nucleus and converts it to a repressor. Cell 89: 1043-1053.

Bejsovic, A. and E. Wieschaus. 1993. Segment polarity gene interactions modulate epidermal patterning in Drosophila embryos. Development 119: 501-517.

Chen, Y. and G. Struhl. 1996. Dual roles for patched in sequestering and transducing hedgehog. Cell 87: 553-563.

Chou, T.-B., E. Noll, and N. Perrimon. 1993. Autosomal P[ovoD1] dominant female-sterile insertions in Drosophila and their use in generating germ-line chimeras. Development 119: 1359-1369.

Concordet, J.-P., K. Lewis, J. Moore, L.V. Goodrich, R.L. Johnson, M.P. Scott, and P.W. Ingham. 1996. Spatial regulation of a zebrafish patched homologue reflects the roles of sonic hedgehog and protein kinase A in neural tube and somite patterning. Development 122: 2835-2846.

Domínguez, M., M. Brunner, E. Hafen, and K. Basler. 1996. Sending and receiving the hedgehog signal: Control by the Drosophila Gli protein cubitus interruptus. Science 272: 1621-1625.

Eaton, S. and T.B. Kornberg. 1990. Repression of ci-D in posterior compartments of Drosophila by engrailed. Genes \& Dev. 4: 1068-1077.

Epstein, D.J., E. Marti, M.P. Scott, and A.P. M CMahon. 1996. Antagonizing CAM P-dependent protein kinase $A$ in the dorsal CNS activates a conserved Sonic hedgehog signaling pathway. Development 122: 2885-2894.

Ericson, J., S. M orton, A. Kawakami, H. Roelink, and T.M. Jessell. 1996. Two critical periods of sonic hedgehog signaling required for the specification of motor neuron identity. Cell 87: 661-673.

Fan, C.-M ., J.A. Porter, C. Chiang, D.T. Chang, P.A. Beachy, and M. Tessier-Lavigne. 1995. Long-range sclerotome induction by Sonic hedgehog: direct role of the amino-terminal cleavage product and modulation by the cyclic AMP signaling pathway. Cell 81: 457-465.

Forbes, A.J., Y. N akano, A.M. Taylor, and P.W. Ingham. 1993. Genetic analysis of hedgehog signaling in the Drosophila embryo. Development (Suppl.): 115-124.

Freedman, N.J. and R.J. Lefkowitz. 1996. Desensitization of G protein-coupled receptors. Recent Prog. Horm. Res. 51: 319353.

Hammerschmidt, M., M.J. Bitgood, and A.P. McM ahon. 1996. Protein kinase $A$ is a common negative regulator of Hedgehog signaling in the vertebrate embryo. Genes \& Dev. 10: 647-658.

Heemskerk, J. and S. DiN ardo. 1994. Drosophila hedgehog acts as a morphogen in cellular patterning. Cell 76: 449-460.

Hepker, J., Q.-T. Wang, C.K. Motzny, R. Holmgren, and T.V. Orenic. 1997. Drosophila cubitus interruptus forms a negative feedback loop with patched and regulates expression of Hedgehog target genes. Devel opment 124: 549-558.

Hidal go, A. and P.W. Ingham. 1990. Cell patterning in the Drosophila segment: Spatial regulation of the segment polarity gene patched. Development 110: 291-302.

Hooper, J. 1994. Distinct pathways for autocrine and paracrine 
wingless signalling in Drosophila embryos. Nature 372: 461464.

Ingham, P.W. 1993. Local ized hedgehog activity controls spatial limits of wingless transcription in the Drosophila embryo. Nature 366: 560-562.

- - . 1995. Signaling by hedgehog family proteins in Drosophila and vertebrate development. Curr. Biol. 5: 492-498.

Inglese, J., N.J. Freedman, W.J. Koch, and R.J. Lefkowitz. 1993. Structure and mechanism of the $\mathrm{G}$ protein-coupled receptor kinases. J. Biol. Chem. 268: 23735-23738.

Jiang, J. and G. Struhl. 1995. Protein kinase A and hedgehog signaling in Drosophila limb devel opment. Cell 80: 563-572.

Johnson, R.L., J.K. Grenier and M .P. Scott. 1995. patched overexpression alters wing disc size and pattern: Transcriptional and post-transcriptional effects on hedgehog targets. Development 121: 4161-4170.

Kalderon, D. 1995. Responses to Hedgehog. Curr. Biol. 5: 580582.

Lane, M.E. and D. Kalderon. 1993. Genetic investigation of CAM P-dependent protein kinase function in Drosophila de velopment. Genes \& Dev. 7: 1229-1243.

- - . 1994. RN A localization al ong the anteroposterior axis of the Drosophila oocyte requires PKA-mediated signal transduction to direct normal microtubule organization. Genes \& Dev. 8: 2986-2995.

Lawrence, P.A. and G. Struhl. 1996. Morphogens, compartments and pattern: Lessons from Drosophila? Cell 85: 951961.

Lepage, T., S.M. Cohen, F.J. Diaz-Benjumea, and S.M. Parkhurst. 1995. Signal transduction by CAMP-dependent protein kinase A in Drosophila limb patterning. Nature 373: 711-715.

Li, W., J.T. Ohlmeyer, M.E. Lane, and D. Kalderon. 1995. Function of protein kinase $A$ in hedgehog signal transduction and Drosophila imaginal disc development. Cell 80: 553-562.

Ma, C., Y. Zhou, P.A. Beachy, and K. M oses. 1993. The segment polarity gene hedgehog is required for progression of the morphogenetic furrow in the developing Drosophila eye. Cell 75: 927-938.

Marigo, V., R.A. Davey, Y. Zuo, J.A. Cunningham, and C.J. Tabin. 1996. Biochemical evidence that Patched is the Hedgehog receptor. Nature 384: 176-179.

Motzny, C.K. and R. Holmgren. 1995. The Drosophila cubitus interruptus protein and its role in the wingless and hedgehog signal transduction pathways. Mech. Dev. 52: 137-150.

Orellana, S.A. and G.S. M cKnight. 1992. Mutations in the cataIytic subunit of CAMP-dependent protein kinase result in unregulated biological activity. Proc. Natl. Acad. Sci. 89: 4726-4730.

Orenic, T.V., D.C. Slusarski, K.L. Kroll, and R.A. Holmgren. 1990. Cloning and characterization of the segment polarity gene cubitus interruptus Dominant of Drosophila. Genes \& Dev. 4: 1053-1067.

Pan, D. and G.M. Rubin. 1995. cAM P-dependent protein kinase and hedgehog act antagonistically in regulating decapentaplegic transcription in Drosophila imaginal discs. Cell 80: 543-552.

Patel, N.H., E. Martin-Blanco, K.G. Coleman, S.J. Poole, M.C. Ellis, T.B. Kornberg, and C.S. Goodman. 1989. Expression of engrailed proteins in arthropods, annelids and chordates. Cell 58: 955-968.

Peifer, M. and A. Bejsovic. 1992. Knowing your neighbors: Cell interactions determine intrasegmental patterning in Drosophila. Trends Genet. 8: 243-249.

Porter, J.A., K.E. Young, and P.A. Beachy. 1996. Cholesterol modification of hedgehog signaling proteins in animal devel- opment. Science 274: 255-259.

Préat, T. 1992. Characterization of Supressor of fused, a complete supressor of the fused segment polarity gene of Drosophila melanogaster. Genetics 132: 725-736.

Préat, T., R. Thérond, C. Lamour-Isnard, B. Limbourg-Bouchon, H. Tricoire, I. Erk, M.C. Mariol, and D. Busson. 1990. A putative serine threonine protein-kinase encoded by the segment-polarity fused gene of Drosophila. Nature 347: 87-89.

Roelink, H., J.A. Porter, C. Chiang, Y. T anabe, D.T . Chang, P.A. Beachy, and T.M. Jessell. 1995. Floor plate and motor neuron induction by different concentrations of the amino-terminal cleavage product of Sonic hedgehog autoproteolysis. Cell 81: 445-456.

Sánchez-Herrero, E., J.P. Couso, J. Capdevila, and I. Guerrero. 1996. The fu gene discriminates between pathways to control dpp expresson in Drosophila imaginal discs. Mech. Dev. 55: 159-170.

Slusarski, D.C., C.K. Motzny, and R. Holmgren. 1995. Mutations that al ter the timing and pattern of cubitus interruptus gene expression in Drosophila melanogaster. Genetics 139: 229-2404.

Stone, D.M., M. Hynes, M. Armanini, T.A. Swanson, Q. Gu, R.L. Johnson, M.P. Scott, D. Pennica, A. Goddard, H. Phillips, M. N oll, J.E. Hooper, F. de Sauvage, and A. Rosenthal. 1996. The tumour-suppressor gene patched encodes a candidate receptor for Sonic hedgehog. Nature 384: 129-134.

Struhl, G., D.A. Barbash, and P.A. Lawrence. 1997. Hedgehog acts by distinct gradient and signal relay mechanisms to organize cell type and cell polarity in the Drosophila abdomen. Development 124: 2155-2165.

Strutt, D.I., V. Wiersdorff, and M. M lodzik. 1995. Regulation of furrow progression in the Drosophila eye by CAMP-dependent protein kinase A. Nature 373: 705-708.

Tabata, T. and T.B. Kornberg. 1994. Hedgehog is a signaling protein with a key role in patterning Drosophila imaginal discs. Cell 76: 89-102.

Thérond, P., G. Alves, B. Limbourg-Bouchon, H. Tricoire, E. Guillemet, J. Brissard-Zahraoui, C. Lamour-Isnard, and D. Busson. 1996a. Functional domains of fused, a serine-threonine kinase required for signaling in Drosophila. Genetics 142: 1181-1198.

Thérond, P.P., J.D. Knight, T. Kornberg, and J.M. Bishop. 1996b. Phosphorylation of the fused protein kinase in response to signaling from hedgehog. Proc. Natl. Acad. Sci. 93: 42244228.

Ungar, A.R. and R.T. M oon. 1996. Inhibition of protein kinase A phenocopies ectopic expression of hedgehog in the CNS of wild-type and cyclops mutant embryos. Dev. Biol. 178: 186191.

van den Heuvel, M. and P.W. Ingham. 1996. smoothened encodes a receptor-like serpentine protein required for hedgehog signaling. Nature 382: 547-551.

Von Ohlen, T., D. Lessing, R. N usse, and J.E. Hooper. 1997. Hedgehog signaling regulates transcription through cubitus interruptus, a sequence-specific DN A binding protein. Proc. Natl. Acad. Sci. 94: 2404-2409.

Yoffe, K.B., A.S. Manoukian, E.L. Wilder, A.H. Brand, and N. Perrimon. 1995. Evidence for engrailed-independent wingless autoregulation in Drosophila. Dev. Biol. 170: 636-650. 


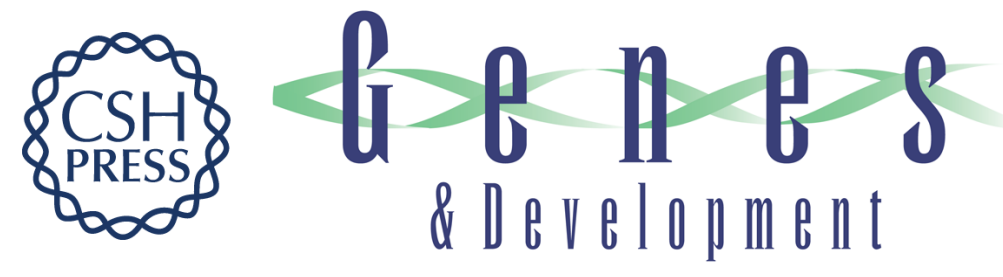

\section{Dual pathways for induction of wingless expression by protein kinase A and Hedgehog in Drosophila embryos}

Johanna Talavera OhImeyer and Daniel Kalderon

Genes Dev. 1997, 11:

Access the most recent version at doi:10.1101/gad.11.17.2250

References This article cites 51 articles, 23 of which can be accessed free at: http://genesdev.cshlp.org/content/11/17/2250.full.html\#ref-list-1

License

Email Alerting

Receive free email alerts when new articles cite this article - sign up in the box at the top Service right corner of the article or click here.

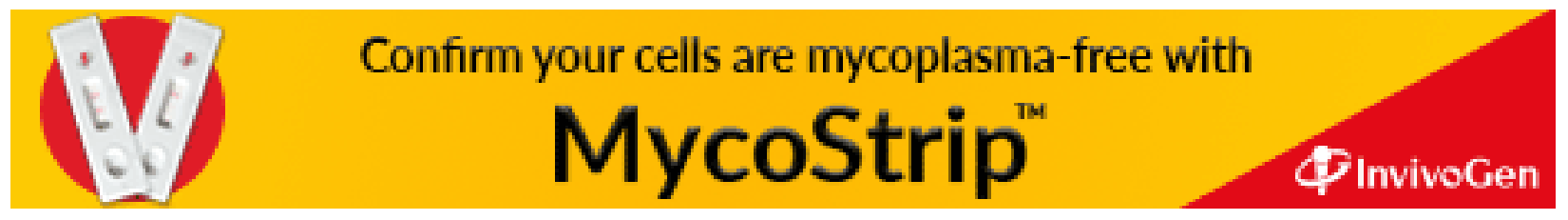

